\title{
Erratum to: Ruwenzoria, a new genus of the Xylariaceae from Central Africa
}

\author{
Marc Stadler • Jacques Fournier • Thomas Læssøe • \\ Cony Decock • Derek Peršoh • Gerhard Rambold
}

Published online: 23 January 2010

(C) German Mycological Society and Springer 2009

\section{Erratum to: Mycol Progress (2009)}

\section{DOI 10.1007/s11557-009-0623-3}

In the original published version of this article, unfortunately, the GenBank Acc. No in Fig. 6 was not inserted. The completed Fig. 6 is given here.

The online version of the original article can be found at http://dx.doi. org/10.1007/s11557-009-0623-3.

M. Stadler $(\bowtie) \cdot$ D. Peršoh · G. Rambold

Lehrstuhl für Pflanzensystematik, Department Mycology,

University of Bayreuth,

Universitätstraße 30, NW1,

95440 Bayreuth, Germany

e-mail: marc.stadler@t-online.de

G. Rambold

e-mail: gerhard.rambold@uni-bayreuth.de

M. Stadler

InterMed Discovery $\mathrm{GmbH}$,

Otto-Hahn-Straße 15,

44227 Dortmund, Germany

J. Fournier

Las Muros,

09420 Rimont, France

e-mail: jacques.fournier@club-internet.fr
T. Læssøe

Department of Biology, University of Copenhagen,

Universitetsparken 15 ,

DK-2100 Copenhagen Ø, Denmark

e-mail: thomasl@bio.ku.dk

\section{Decock}

Mycothèque de l' Université catholique de Louvain,

(BCCM/MUCL, MBLA), Université catholique de Louvain,

Place Croix du Sud 3,

1348Louvain-la-Neuve, Belgium

e-mail: cony.decock@uclouvain.be

D. Peršoh

Systematische Botanik und Mykologie,

Ludwig-Maximilians-Universität München,

Menzinger Straße 67,

80638 München, Germany

e-mail: persoh@biologie.uni-muenchen.de 


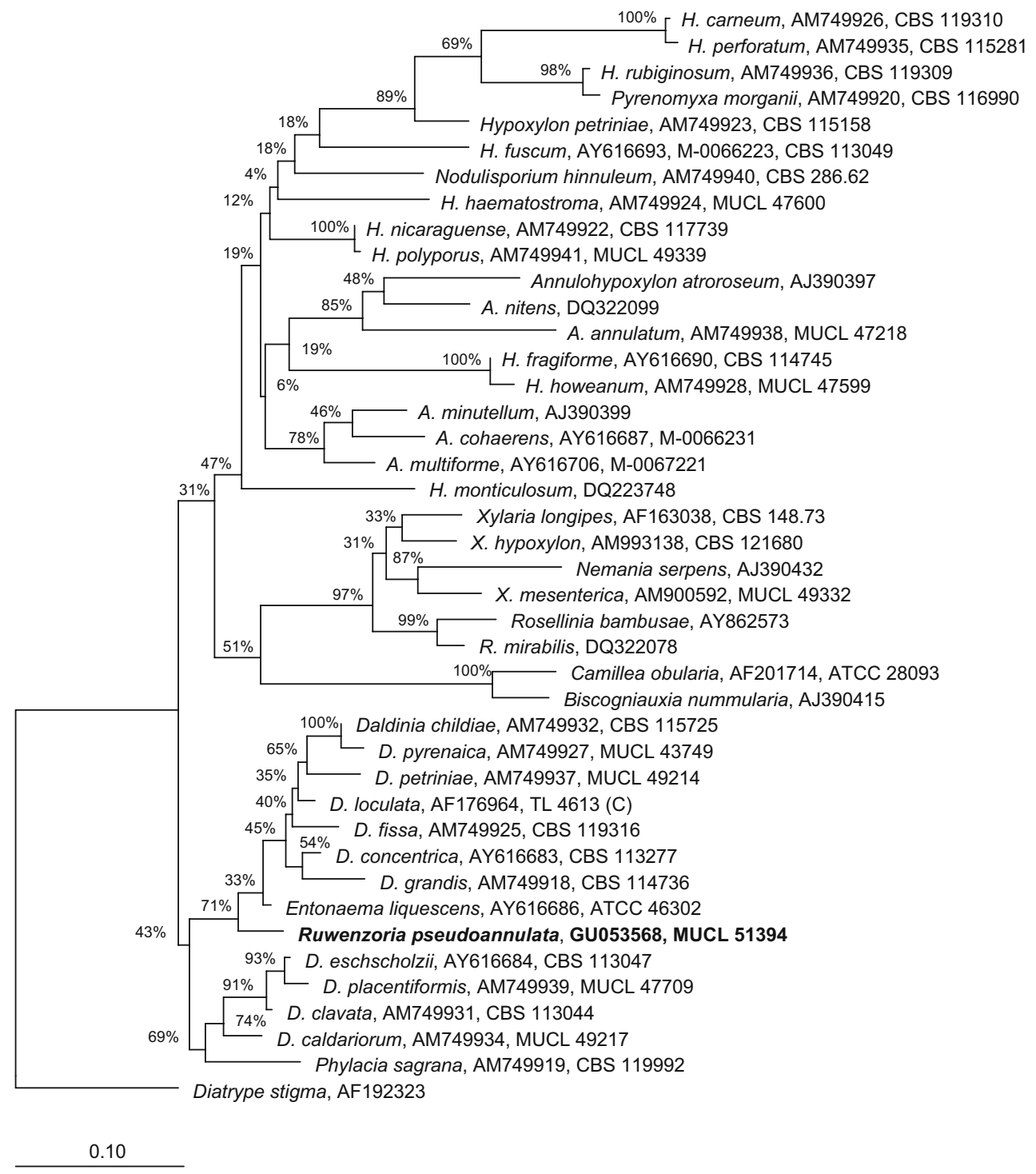

